\title{
Fusion of infrared images with 3D GIS model for environmental imaging
}

\author{
by B. Bukowska-Belniak*, M. Lupa*, A. Leśniak*
}

\begin{abstract}
*AGH University of Science and Technology, al. Mickiewicza 30, 30-059 Krakow, Poland, bukowska@agh.edu.pl,mlupa@agh.edu.pl, lesniak@agh.edu.pl
\end{abstract}

\begin{abstract}
This paper presents the method of $3 \mathrm{D}$ visualization of environmental thermal images. Method use thermal images of experimental river embankment. This kind of images can be useful for leaks and thermal anomalies detection. The authors use GIS, due to the monitored data visualization capabilities and their integration into a single coherent model.

The infrared images, taken from different perspectives and distances, are placed on the 3D model of the soil embankment. The special method to precociously contact and remove distortion of images was applied. This approach allows for analysis of data from different types of measurements methods including infrared camera.
\end{abstract}

\section{Introduction}

ISMOP (Computer System for Monitoring River Embankments) is a research project for complex system of monitoring static and dynamic state of embankments [1]. The project includes putting up an experimental embankment in scale 1:1. The experimental embankment consists of two branches, which are 150 meters long and 4.5 meter high with diversified soil type and structure. The specialised, measurement system is installed in experimental embankment to monitoring its internal parameters. Flood embankment's parameters are measured by many kinds of sensors and measurement methods [2]. Parameters measured inside the experimental embankment are: pore pressure, tension, displacement and temperature. Internal measurements are performed using point or linear (fiber optics) sensors permanently mounted inside the embankment's structure. Additionally, some external measurements can be done, for example geodetic, radar, geophysical and thermographical measurements. The weather parameters and water level are also measured. With such artificial embankment it is possible to simulate floods in the assumed flooding scenarios using water from Vistula river.

Thermography a supplement method of monitoring will be used during flooding experiments. First infrared observations during flooding scenario was successfully performed on small embankment [3].

In case of such large embankment, due to the limited field of view of thermographic camera it is not possible to measure the whole object in each moment using one device. Extension of the distance would involve the loss of spatial resolution. To maintain high spatial resolution the camera executes the set of images taken along the embankment. The measurement is made from a single vantage point, which causes geometric distortion of images. There is a need to develop an efficient and precise methods of fusion of thermal images for such 3D structure as the experimental embankment before embarking on flood experiments.

\section{Method}

Adaptations of 3D modeling can be found in [4], where the authors present an integrated model for geological visualization purposes. Interesting approach of GIS-based environment for infrared thermography analysis of buildings is also shown in [5]. It is also worth to mention about 3D GIS modeling for urban purposes, which were included in paper [6].

The authors decided to use Geographic Information Systems (GIS), due to the monitored data visualization capabilities and their integration into a single coherent model. The three-dimensional vector models of the terrain and the embankment were made based on geodetic measurements. The models were stored in the of 3D shapefile format.

Afterwards, the models were divided into few sections that correspond to the locations of sensors profiles and the places of thermographical measurements. The final stage of the project consists of applying textures (panoramic image of the thermal measurements, formed by joining adjacent images) to the relevant sections of the model. 


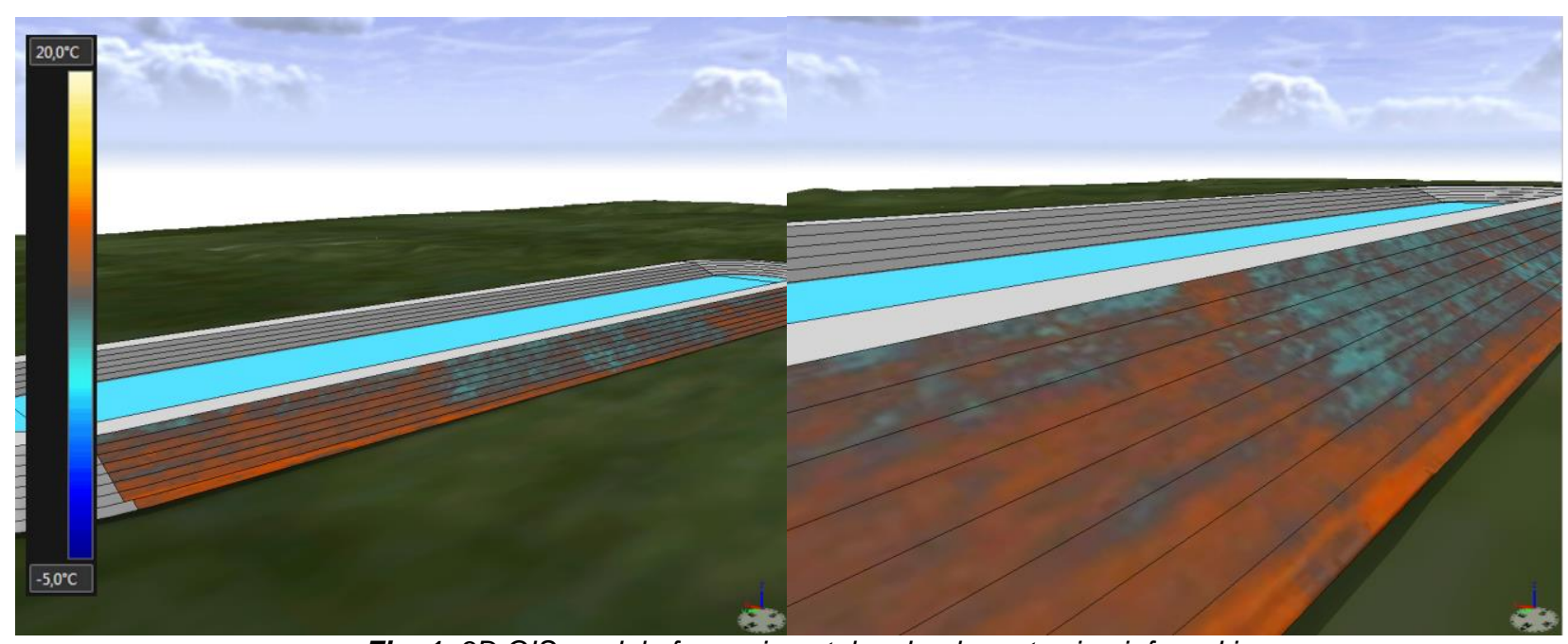

Fig. 1. 3D GIS model of experimental embankment using infrared images.

\section{Conclusions}

Presented method allows for fusion registered set of infrared images of 3D environmental object like experimental embankment. This approach allows for concurrent analysis of data e.g. from sensors and infrared camera. Using this method of visualization it will be possible to create a sequence of images of a 3D object during the flooding experiment. Next step is creating the visualization movies. This method also allows to compare thermal changes on embankment's surface in time. It can help in leakages detection and localization.

It is planned in future to install on the experimental embankment infrared reflectors and absorbers in order to establish the position of the images to the embankment's surface. Also more measurements including thermography during flooding experiments is planned.

This work was supported by the National Centre of Research and Development (NCBiR), Poland, project PBS1/B9/18/2013 (no. 180535) [1]

This work was partly supported by the AGH University of Science and Technology, Faculty of Geology, Geophysics and Environmental Protection, as part of statutory project no. 11.11.140.613.

\section{REFERENCES}

[1] ISMOP - Computer System for Monitoring River Embankments (in Polish: Informatyczny System Monitorowania Obwalowań Przeciwpowodziowych), www.ismop.edu.pl.

[2] Stanisz J., Borecka A., Leśniak A., Zieliński K.: Wybrane systemy monitorujące obwałowania przeciwpowodziowe [Selected levee monitoring systems], „Przegląd Geologiczny” 2014, vol. 62, nr 10/2, p. 699703.

[3] Bukowska-Belniak B., Leśniak A., Kessler D., "Thermographical monitoring of leak processes in embankments", AITA $2015,13^{\text {th }}$ international workshop on Advanced Infrared Technology \& Applications: proceedings, pp. 7678, 2015.

[4] Wang Y., Wu L., Shi W. Liu X., "On 3D GIS spatial modeling". ISPRS Workshop on Updating Geo-spatial Databases with Imagery $\&$ The $5^{\text {th }}$ ISPRS Workshop on DMGISs, ISPRS Archives, Vol. XXXVI-4/W54, pp. 237240, 2007.

[5] Previtali M., Erba S., Rosina E., Redaelli V., Scaioni M., Barazetti L., "Generation of a GIS-based environment for infrared thermography analysis of buildings", Infrared Remote Sensing and Instrumentation XX Proc. of SPIE Vol. 8511, 85110U, doi:10.1117/12.930050, 2012.

[6] Koninger A., Bartel S., "3D-GIS for Urban Purposes" Geolnformatica, 2, 1 pp. 79-103, 1998. 